\title{
Comparison of Three Different Techniques for Dual-Energy Subtraction Imaging in Digital Radiography: A Signal-to-Noise Analysis
}

\author{
Chris C. Shaw and David Gur
}

\begin{abstract}
Dual-energy subtraction imaging techniques allow the tissue and bone structures in the patient to be visualized and studied in two separate images, thus removing the obscurity associated with overlapping of the two structures. In addition, they allow the subtraction image signals to be used for quantifying the tissue and bone thicknesses. Thus, capability for dual-energy subtraction imaging is often incorporated with new digital radiography systems. There are three different approaches to dual-energy image subtraction imaging techniques. Among them, the dual-kilovolt (peak) $[k V(p)]$ and sandwich detector techniques have been two widely used approaches. A third approach is the single-kV(p) dual-filter technique, which allows some flexible control of the spectra while avoiding the technical complexity of $k V(p)$ value switching in slitscan imaging. In this report, the noise properties associated with these three techniques are studied and compared by computing the noise variances in the subtraction image signals as a function of the $\mathrm{kV}(\mathrm{p})$ values and filter thicknesses. It was found that the dual-kVp technique results in the least noisy subtraction images, whereas the dual-filter technique results in slightly less noisy subtraction images than the sandwich detector technique. Following optimization of the $k V(p)$ value and filter thicknesses, the dual-filter and sandwich detector techniques result in a noise level of approximately three and four times higher than that resulted from the dual-kV(p) technique, respectively.

Copyright $\odot 1992$ by W.B. Saunders Company
\end{abstract}

KEY WORDS: medical imaging, digital radiography, dual-energy subtraction imaging.

A DVANCES IN DIGITAL radiography techniques in the past decade have opened the door to the implementation of various image acquisiton, processing, storage, and display ca-

From the Department of Diagnostic Radiology, University of Pittsburgh, Pittsburgh, PA.

Supported by research grants no. HL39299 from the National Heart, Lung and Blood Institute and no. CA51248 from the National Cancer Institute.

Address reprint requests to Chris C. Shaw, PhD, A-441 Scaife Hall, Radiological Imaging Division, University of Pittsburgh, Pittsburgh, PA 15261.

Reprinted with permission from SPIE Vol 1651: Medical Imaging VI: Instrumentation, 1992.

Copyright 1992 by The Society of Photo-Optical Instrumentation Engineers

0-8194-0803-4/92/\$4.00 pabilities that have been difficult if not impossible with the conventional screen-film techniques. One such capability is the dual-energy subtraction imaging technique. With this technique, low- and high-energy $\mathrm{x}$-ray spectra are used to acquire two images, which are synthesized into a tissue-specific image and a bonespecific image. In the tissue-specific image, the bone structures are canceled out. Similarly, in a bone-specific image, the tissue structures are canceled out. This background cancellation has been shown to improve the clarity of the anatomical details in general and to aid certain diagnostic tasks, the most notable example being the detection of lung nodules overlapping with ribs in chest imaging. ${ }^{1,2}$ Various techniques for implementing the dual-energy subtraction imaging capability have been investigated.

\section{TECHNIQUES FOR DUAL-ENERGY SUBTRACTION IMAGING}

\section{Dual-Kilvolt (Peak) Technique}

With the dual-kilovolt (peak) $[\mathrm{kV}(\mathrm{p})]$ technique, the low- and high-energy spectra are generated at two different $\mathrm{kV}(\mathrm{p})$ levels requiring two separate exposures for low- and highenergy image acquisition. This can be achieved by performing the entire image-acquisition procedure at two different $\mathrm{kV}(\mathrm{p})$ levels. The dual$\mathrm{kV}(\mathrm{p})$ approach can be used with either broad$\operatorname{area}^{3}$ or slit-scan ${ }^{4}$ imaging techniques. However, when patient or anatomical motions are involved, the time between the two images will result in significant motion artifacts. With slitscan imaging using a linear detector array, it is possible to rapidly switch the $\mathrm{kV}(\mathrm{p})$ level during acquisition of each image line to minimize the motion artifacts. Because of its complexity, it has only been successfully implemented with a low-resolution spot-scan system and has been used mainly for bone mineral measurement. Despite technical complexity and potential difficulty, the rapid $\mathrm{kV}(\mathrm{p})$ value change seems to be a viable approach to implementing the dual$k V(p)$ technique for dual-energy subtraction 
imaging without motion artifacts. High-speed filter change has also been used with a spot-scan system to further improve the separation between the low- and high-energy spectra; however, it appears to be an extremely difficult task to implement with a slit-scan imaging system.

\section{Single $k V(p)$ Dual-Filter Technique}

The dual-kV(p) tehcnique can be significantly simplified by using double-slit collimation to generate two x-ray fan beams that are independently filtered for low- and high-energy image acquisition. Two linear detector arrays are required for simultaneous low- and highenergy image acquisition during the scan. A logical choice for filter materials would be tungsten and copper for the low- and highenergy beams. Copper filtration shifts the $\mathrm{x}$-ray spectrum toward the $\mathrm{kV}(\mathrm{p})$. Tungsten, on the other hand, attenuates the overall beam intensity while shifting the $\mathrm{x}$-ray spectrum towards its $\mathrm{K}$-edge energy at $69.5 \mathrm{keV}$. The use of these two filters results in the low- and high-energy spectra required for dual-energy subtraction imaging. Although the spectral separation achieved with this method is not as good as with the dual-kV(p) technique, the resulting simplification in implementation may be worthwhile in some applications.

\section{Sandwich Detector Technique}

The sandwich detector technique uses two detectors separated by a filter plate for simultaneous low- and high-energy image acquisition. It has been successfully used in digital radiography techniques using either a linear detector array $^{5}$ or storage phoshors ${ }^{6-8}$ as the $x$-ray detector. With this technique, the front detector and the interdetector filter together filter the x-ray spectrum (already attenuated by the patient's tissue) and shift it toward the $k V(p)$ level. Because the order of attenuation and filtration is irrelevant as far as transmission is concerned, this is the equivalent of providing a higherenergy spectrum for image acquisition with the back detector. The most widely used filter material for the sandwich detector technique is copper. Although other materials have been tested, the difference in the resulting image quality is minimal.

\section{Selection of Techniques}

The selection of a dual-energy subtraction technique for a digital radiography system is determined by several factors. Although the choices are often limited by the shape, configuration, and operating characteristics of the detector used, there is often more than one approach that can be used to implement the dual-energy subtraction technique with a specific imaging system. Therefore, it is worthwhile to compare the three techniques described for image quality and other considerations.

The image quality of most imaging techniques can be characterized by (1) signal response, (2) spatial-resolution properties, and (3) noise properties or low-contrast performance. The signal responses of a dual-energy subtraction imaging technique are the range and linearity of tissue and bone signals as the thickness measurement. The signal response is crucial to quantitative imaging studies such as bone density measurement. In regular (qualitative) imaging studies, signal response is not as important and will not be considered in this report. The spatialresolution properties of dual-energy subtraction images could be degraded in relation to the raw images; however, the causes of such degradation are not intrinsic to the dual-energy subtraction imaging processing itself. They are mostly related to the time lapse during image acquisition, misregistration of the detectors, or patient motion. Our main concern in this report is to show how the noise properties of the three different techniques compare with each other. Because the detectors used in a digital radiography system are often operated in the quantumlimited exposure range, we deal only with the $\mathrm{x}$-ray quantum noise present in the raw image data and propagated to the subtraction images through the subtraction algorithms.

\section{THEORY}

To study the noise properties, the noise variances in tissue and bone subtraction images were derived as a function of the noise ratios in low- and high-energy $x$-ray measurements and parameters computed from the attenuation coefficients averaged over the detected $\mathrm{x}$-ray spectra. Similar derivations have been previously described and used to study effects of scatter in 
dual-energy subtraction imaging. ${ }^{9}$ The following derivation, taking a more general approach, is based on the use of a broad-spectrum x-ray beam and nonlinear subtraction algorithm.

\section{Dual-Energy Subtraction Algorithm}

In dual-energy subtraction imaging, low- and high-energy $\mathrm{x}$-ray image data are processed by a special subtraction algorithm to cancel out the background structures and generate the tissueand bone-specific subtraction images. During processing, quantum noises are propagated from the original image data into the subtraction images. Thus, noise level in the subtraction images depends on three factors: noise ratio in the raw image data, x-ray spectra, and the subtraction algorithm used. Because polyenergetic x-rays are assumed to be used, as in practical applications, a nonlinear subtraction algorithm should be used to avoid beamhardening effect and to ensure the accuracy of the tissue and bone signals as the thickness measurements. Such algorithms have been developed and reported elsewhere. ${ }^{10,11}$ Although these algorithms vary in their approaches and accuracies, for the purpose of this report the two functions $f_{a}$ and $f_{b}$ can be determined and used to accurately convert the $\mathrm{x}$-ray densities $\mathrm{D}_{\mathrm{I}}$ and $\mathrm{D}_{\mathrm{h}}$ into the tissue- and bone-thickness signals $t_{a}$ and $t_{b}$ in centimeters as follows:

$$
\mathrm{t}_{\mathrm{a}}=\mathrm{f}_{\mathrm{a}}\left(\mathrm{D}_{\mathrm{l}}, \mathrm{D}_{\mathrm{h}}\right) \quad \text { (Equation 1) }
$$

and

$$
t_{b}=f_{b}\left(D_{1}, D_{h}\right), \quad \text { (Equation 2) }
$$

where, in analogy to the optical densities, the x-ray densities $D_{l}$ and $D_{h}$ are defined to be $\ln \left(\mathrm{p}_{\mathrm{l}} / \mathrm{p}_{\mathrm{l}}\right)$ and $\ln \left(\mathrm{p}_{\mathrm{h}}{ }^{0} / \mathrm{p}_{\mathrm{h}}\right)$, respectively, $\mathrm{p}_{\mathrm{I}}$ and $\mathrm{p}_{\mathrm{l}}{ }^{0}$ are the attenuated and unattenuated signals from the low-energy spectrum, and $p_{h}$ and $p_{h}{ }^{0}$ are the attenuated and unattenuated signals from the high-energy spectrum. We also assume that scattered radiation and any optical scatter are properly controlled or corrected for so that $\mathrm{p}_{\mathrm{l}}^{0}, \mathrm{p}_{\mathrm{l}}, \mathrm{p}_{\mathrm{h}}{ }^{0}$, and $\mathrm{p}_{\mathrm{h}}$ represent true primary measurements. Knowing the spectra of the incident $\mathrm{x}$-rays, $\mathrm{p}_{\mathrm{l}}^{0}, \mathrm{p}_{\mathrm{h}}{ }^{0}, \mathrm{p}_{\mathrm{l}}$ and $\mathrm{p}_{\mathrm{h}}$ can be expressed as follows:

$$
\mathrm{p}_{1, \mathrm{~h}}{ }^{0}=\int d \mathrm{ER}_{\mathrm{l}, \mathrm{h}} \phi_{\mathrm{l}, \mathrm{h}}(\mathrm{E}) \mathrm{Q}(\mathrm{E}) \quad(\text { Equation 3) }
$$

and

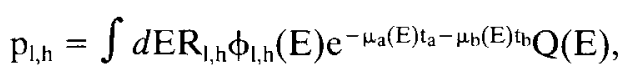

(Equation 4)

where $R_{l}$ and $R_{h}$ are the unattenuated low- and high-energy x-ray exposures in milliroentgens at the detector plane, $\phi_{l}(E)$ and $\phi_{h}(E)$ are the unattenuated photon flux per unit exposure per unit energy (photons $/ \mathrm{cm}^{2} / \mathrm{mR} / \mathrm{keV}$ ), and $Q(E)$ is the detector response function and represents the signal generated by each photon with an energy near $\mathrm{E}(\mathrm{keV}) . \mu_{a}(E)$ and $t_{a}$ are the linear attenuation coefficients $(1 / \mathrm{cm})$ and thickness in (centimeters) for soft tissue, and $\mu_{b}(E)$ and $t_{b}$ are those for bone.

During the $\mathrm{x}$-ray detection process, only part of the $\mathrm{x}$-ray photon energy is converted into fluorescent light in an $\mathrm{x}$-ray scintillator. In digital imaging, this light is directly or indirectly (though an image intensifier and/or optical coupling) detected by a light-sensitive imager, eg, television target or charged-coupled device. The rest of the $\mathrm{x}$-ray photon energy is dissipated into heat and does not conribute to image signals. In reality, the ratio of the $\mathrm{x}$-ray photon energy that contributes to the image signals varies slightly with the $\mathrm{x}$-ray energy, E. However, for good approximation, we can assume that this ratio is constant for all diagnostic energies (10 to $120 \mathrm{keV})$ and $\mathrm{Q}(\mathrm{E})$ is proportional to E. Thus, Equation 3 and 4 may be rewritten as follows:

$$
\mathrm{p}_{1, \mathrm{~h}}{ }^{0}=\int d \mathrm{ER}_{\mathrm{l}, \mathrm{h}} \phi_{1, \mathrm{~h}}(\mathrm{E}) \alpha \mathrm{E} \quad \text { (Equation 5) }
$$

and

$$
\mathrm{p}_{\mathrm{l}, \mathrm{h}}=\int d \mathrm{ER}_{\mathrm{l,h}} \phi_{\mathrm{l}, \mathrm{h}}(\mathrm{E}) \mathrm{e}^{-\mu_{\mathrm{a}}(\mathrm{E}) \mathrm{t}_{\mathrm{a}}-\mu_{\mathrm{b}}(\mathrm{E}) \mathrm{t}_{\mathrm{b}}} \alpha \mathrm{E}
$$

(Equation 6)

where $\alpha$ is a proportional constant. Thus, the $\mathrm{x}$-ray densities $\mathrm{D}_{\mathrm{l}}$ and $\mathrm{D}_{\mathrm{h}}$ may be expressed as a function of $t_{a}$ and $t_{b}$ as follows:

$$
\begin{aligned}
\mathrm{D}_{1}= & \mathrm{F}_{1}\left(\mathrm{t}_{\mathrm{a}}, \mathrm{t}_{\mathrm{b}}\right)=\ln \left[\mathrm{p}_{\mathrm{l}}^{0} / \mathrm{p}_{\mathrm{l}}\right] \\
= & \ln \left[\int d \mathrm{ER}_{\mathrm{l}} \phi_{\mathrm{l}}(\mathrm{E})\right. \\
& \left.\times \mathrm{E} / \int d \mathrm{ER}_{\mathrm{l}} \phi_{\mathrm{l}}(\mathrm{E}) \mathrm{e}^{-\mu_{\mathrm{a}}(\mathrm{E}) \mathrm{t}_{\mathrm{a}}-\mu_{\mathrm{b}}(\mathrm{E}) \mathrm{t}_{\mathrm{b}} \mathrm{E}}\right]
\end{aligned}
$$

(Equation 7) 
and

$$
\begin{aligned}
\mathrm{D}_{\mathrm{h}}= & \mathrm{F}_{\mathrm{h}}\left(\mathrm{t}_{\mathrm{a}}, \mathrm{t}_{\mathrm{b}}\right)=\ln \left[\mathrm{p}_{\mathrm{h}}{ }^{0} / \mathrm{p}_{\mathrm{h}}\right] \\
= & \ln \left[\int d \mathrm{ER}_{\mathrm{h}} \phi_{\mathrm{h}}(\mathrm{E})\right. \\
& \left.\times \mathrm{E} / \int d \mathrm{ER}_{\mathrm{h}} \phi_{\mathrm{h}}(\mathrm{E}) \mathrm{e}^{-\mu_{\mathrm{a}}(\mathrm{E}) \mathrm{t}_{\mathrm{a}}-\mu_{\mathrm{h}}(\mathrm{E}) \mathrm{t}_{\mathrm{b}}} \mathrm{E}\right] .
\end{aligned}
$$

(Equation 8)

The major tasks of dual-energy subtraction imaging are to determine $f_{a}\left(D_{l}, D_{h}\right)$ and $f_{b}$ $\left(D_{l}, D_{h}\right)$ as the inverse functions for $F_{l}\left(t_{a}, t_{b}\right)$ and $F_{h}\left(t_{a}, t_{b}\right)$ and to use them to convert the pixel-by-pixel measurement of $D_{1}$ and $D_{h}$ into the thickness information, $t_{a}$ and $t_{b}$. Although it is not absolutely necessary to convert the $\mathrm{x}$-ray signals $\mathrm{p}_{\mathrm{l}}$ and $\mathrm{p}_{\mathrm{l}}^{0}$ into $\mathrm{x}$-ray densities for such conversion, such practice offers the advantage of dealing with a dimensionless quantity. This advantage will become clear once the noise variance is derived.

\section{Noise Variance}

The low-contrast performance of dual-energy subtraction images is dictated by the noise propagated from the $\mathrm{x}$-ray measurements represented by $\mathrm{p}_{\mathrm{l}}{ }^{0}, \mathrm{p}_{\mathrm{h}}{ }^{0}, \mathrm{p}_{1}$ and $\mathrm{p}_{\mathrm{h}}$. Although signals through a known thickness of soft tissue can still be used for calibration to lessen the dynamic range requirement, such action may be unnecessary because of the superior dynamic range available with most detectors used in digital radiography. Thus, we can assume that $\mathrm{p}_{1}^{0}$ and $\mathrm{p}_{\mathrm{h}}{ }^{0}$ are measured as open-field air signals (ie, without any attenuating material or patient in the $\mathrm{x}$-ray beams) in the calibration procedure. Noise levels in these measurements can be minimized to an insignificant level with sufficiently high exposures (while maintaining the shape of $\mathrm{x}$-ray spectra). Thus, noise levels in $\mathrm{p}_{1}$ and $p_{h}{ }^{0}$ can be assumed to be zero. Because $p_{1}$ and $\mathrm{p}_{\mathrm{h}}$ are independently measured, the noise variance in tissue- and bone-image signals, $\sigma_{\mathrm{t}_{\mathrm{a}}}{ }^{2}$ and $\sigma_{\mathbf{t}_{\mathrm{b}}}{ }^{2}$, may be expressed as the weighted sum of the variances in measuring $p_{1}$ and $p_{h}, \sigma_{p_{l}}{ }^{2}$ and $\sigma_{\mathrm{ph}_{\mathrm{h}}}{ }^{2}$, as follows:

$$
\sigma_{\mathrm{t}_{\mathrm{a}}}^{2}=\left(\partial \mathrm{f}_{\mathrm{a}} / \partial \mathrm{D}_{\mathrm{l}}\right)^{2}{\sigma_{\mathrm{D}_{1}}}^{2}+\left(\partial \mathrm{f}_{\mathrm{a}} / \partial \mathrm{D}_{\mathrm{h}}\right)^{2}{\sigma_{\mathrm{D}_{\mathrm{h}}}}^{2}
$$

(Equation 9) and

$$
\sigma_{\mathrm{t}_{\mathrm{h}}}^{2}=\left(\partial \mathrm{f}_{\mathrm{b}} / \partial \mathrm{D}_{1}\right)^{2}{\sigma_{\mathrm{D}_{1}}}^{2}+\left(\partial \mathrm{f}_{\mathrm{b}} / \partial \mathrm{D}_{\mathrm{h}}\right)^{2}{\sigma_{\mathrm{D}_{\mathrm{h}}}}^{2}
$$

(Equation 10)

Notice that because $\mathrm{p}_{1}$ and $\mathrm{p}_{\mathrm{h}}$ are uncorrelated to each other, there is no cross-term in either equation. Because $\mathrm{D}_{1}=\ln \left[\mathrm{p}_{1}^{0} / \mathrm{p}_{1}\right], \sigma_{\mathrm{D}_{1}}=\left(\partial \mathrm{D}_{1} /\right.$ $\left.\partial \mathrm{p}_{1}\right) \sigma_{\mathrm{p}_{1}}=\sigma_{\mathrm{p}_{1}} / \mathrm{p}_{1}$ similarly $\sigma_{\mathrm{D}_{1}}=\left(\partial \mathrm{D}_{1} / \partial \mathrm{p}_{\mathrm{l}}\right) \sigma_{\mathrm{p}_{1}}=$ $\sigma_{\mathrm{p}_{1}} / \mathrm{p}_{1}$. Thus, the noise fluctuation levels in the $\mathrm{x}$-ray densities, $\mathrm{D}_{1}$ and $\mathrm{D}_{\mathrm{h}}$, are the noise ratios in the low- and high-energy $x$-ray image signals and Equations 9 and 10 can be rewritten as follows:

$$
\sigma_{\mathrm{t}_{\mathrm{a}}}{ }^{2}=\mathrm{k}_{\mathrm{al}}{ }^{2}\left(\sigma_{\mathrm{p}_{\mathrm{p}}} / \mathrm{p}_{\mathrm{l}}\right)^{2}+\mathrm{k}_{\mathrm{ah}}{ }^{2}\left(\sigma_{\mathrm{p}_{\mathrm{h}}} / \mathrm{p}_{\mathrm{h}}\right)^{2}
$$

(Equation 11)

and

$$
\sigma_{\mathrm{t}_{\mathrm{b}}}^{2}=\mathrm{k}_{\mathrm{bl}}^{2}\left(\sigma_{\mathrm{p}_{\mathrm{l}}} / \mathrm{p}_{\mathrm{l}}\right)^{2}+\mathrm{k}_{\mathrm{bh}}^{2}\left(\sigma_{\mathrm{P}_{\mathrm{h}}} / \mathrm{p}_{\mathrm{h}}\right)^{2},
$$

(Equation 12)

where $k_{i j}$ is defined to be $\partial \mathrm{f}_{\mathrm{i}} / \partial \mathrm{D}_{\mathrm{j}}(\mathrm{i}=\mathrm{a}, \mathrm{b}$; $\mathrm{j}=\mathrm{l}, \mathrm{h})$, and $\sigma_{\mathrm{p}_{\mathrm{j}}} / \mathrm{p}_{\mathrm{j}}$ are the noise ratios in low-energy and high-energy $\mathrm{x}$-ray signals respectively. Obviously, $\mathrm{k}_{\mathrm{ij}}$ values are functions of the $\mathrm{x}$-ray densities or, alternatively, can be evaluated as a function of the input $\mathrm{x}$-ray spectrum, tissue and bone thicknesses. However, because the functions $f_{i}$ are not explicitly known, an indirect method is used to compute the $\mathbf{k}_{\mathrm{ij}}$ value. With this method, the average attenuation coefficients $\mu_{i j}$, defined as $\partial F_{j} / \partial t_{i}(i=a, b ; j=1, h)$, will first be evaluated and then used to compute the $\mathrm{k}_{\mathrm{ij}}$ values.

From Equations 7 and 8 the variations of $D_{1}$ and $\mathrm{D}_{\mathrm{h}}, d \mathrm{D}_{1}$ and $d \mathrm{D}_{\mathrm{h}}$, may be expressed as a linear combination of $d \mathrm{t}_{\mathrm{a}}$ and $d \mathrm{t}_{\mathrm{b}}$ as follows:

$$
\begin{aligned}
d \mathrm{D}_{\mathrm{l}} & =\left(\partial \mathrm{F}_{\mathrm{l}} / \partial \mathrm{t}_{\mathrm{a}}\right) d \mathrm{t}_{\mathrm{a}}+\left(\partial \mathrm{F}_{\mathrm{l}} / \partial \mathrm{t}_{\mathrm{b}}\right) d \mathrm{t}_{\mathrm{b}} \\
& =\mu_{\mathrm{a} \mid} d \mathrm{t}_{\mathrm{a}}+\mu_{\mathrm{b}} d \mathrm{t}_{\mathrm{b}} \quad \text { (Equation 13) }
\end{aligned}
$$

and

$$
\begin{aligned}
d \mathrm{D}_{\mathrm{h}} & =\left(\partial \mathrm{F}_{\mathrm{h}} / \partial \mathrm{t}_{\mathrm{a}}\right) d \mathrm{t}_{\mathrm{a}}+\left(\partial \mathrm{F}_{\mathrm{h}} / \partial \mathrm{t}_{\mathrm{b}}\right) d \mathrm{t}_{\mathrm{b}} \\
& =\mu_{\mathrm{ah}} d \mathrm{t}_{\mathrm{a}}+\mu_{\mathrm{bh}} d \mathrm{t}_{\mathrm{b}} . \quad \text { (Equation 14) }
\end{aligned}
$$

Conversely, from Equations 1 and 2, $d \mathrm{t}_{\mathrm{a}}$ and $d \mathrm{t}_{\mathrm{b}}$ may be expressed as a linear combination of $d \mathrm{D}_{1}$ 
and $d \mathrm{D}_{\mathrm{h}}$ as follows:

$$
\begin{aligned}
d \mathrm{t}_{\mathrm{a}} & =\left(\partial \mathrm{f}_{\mathrm{a}} / \partial \mathrm{D}_{1}\right) d \mathrm{D}_{1}+\left(\partial \mathrm{f}_{\mathrm{a}} / \partial \mathrm{D}_{\mathrm{h}}\right) d \mathrm{D}_{\mathrm{h}} \\
& =\mathrm{k}_{\mathrm{al}} d \mathrm{D}_{1}+\mathrm{k}_{\mathrm{ah}} d \mathrm{D}_{\mathrm{h}} \quad \text { (Equation 15) }
\end{aligned}
$$

and

$$
\begin{aligned}
d \mathrm{t}_{\mathrm{b}} & =\left(\partial \mathrm{f}_{\mathrm{b}} / \partial \mathrm{D}_{1}\right) d \mathrm{D}_{\mathrm{l}}+\left(\partial \mathrm{f}_{\mathrm{b}} / \partial \mathrm{D}_{\mathrm{h}}\right) d \mathrm{D}_{\mathrm{h}} \\
& =\mathrm{k}_{\mathrm{bl}} d \mathrm{D}_{1}+\mathrm{k}_{\mathrm{bh}} d \mathrm{D}_{\mathrm{h}} . \quad \text { (Equation 16) }
\end{aligned}
$$

Thus, the coefficients $\mu_{\mathrm{ij}}$ and $\mathrm{k}_{\mathrm{ij}}$ can be considered as elements of two $2 \times 2$ matrices that are inverse to each other and $\mathrm{k}_{\mathrm{ij}}$ can be evaluated as the inverse matrix of $\mu_{\mathrm{ij}}$ as follows:

$\mathrm{k}_{\mathrm{al}}=\mu_{\mathrm{bh}} /\left(\mu_{\mathrm{al}} \mu_{\mathrm{bh}}-\mu_{\mathrm{ah}} \mu_{\mathrm{bl}}\right)$,

(Equation 17)

$\mathrm{k}_{\mathrm{ah}}=-\mu_{\mathrm{bl}} /\left(\mu_{\mathrm{al}} \mu_{\mathrm{bh}}-\mu_{\mathrm{ah}} \mu_{\mathrm{bl}}\right)$,

$\mathrm{k}_{\mathrm{bl}}=-\mu_{\mathrm{ah}} /\left(\mu_{\mathrm{al}} \mu_{\mathrm{bh}}-\mu_{\mathrm{ah}} \mu_{\mathrm{bl}}\right)$,

and

$\mathrm{k}_{\mathrm{bh}}=\mu_{\mathrm{al}} /\left(\mu_{\mathrm{al}} \mu_{\mathrm{bh}}-\mu_{\mathrm{ah}} \mu_{\mathrm{bl}}\right)$.

(Equation 20)

However, using Equations 7 and $8, \mu_{\mathrm{ij}}$ or $\partial \mathrm{F}_{\mathrm{j}} / \partial \mathrm{t}_{\mathrm{i}}$ can be explicitly derived and expressed as follows:

$\mu_{\mathrm{ij}}=\left[\int \mu_{\mathrm{i}}(\mathrm{E}) d \mathrm{ER}_{\mathrm{j}} \phi_{\mathrm{j}}(\mathrm{E}) \mathrm{e}^{\left.-\mu_{\mathrm{a}}(\mathrm{E}) \mathrm{t}_{\mathrm{a}}-\mu_{\mathrm{b}}(\mathrm{E}) \mathrm{t}_{\mathrm{b}} \mathrm{E}\right] /}\right.$

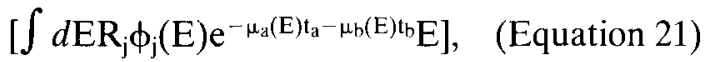

where $i=\mathrm{a}, \mathrm{b}$ and $j=1, \mathrm{~h}$. Equation 21 shows that $\mu_{\mathrm{ij}}$ has the meaning of the average attenuation coefficient for the material $i$ ( $a$ or $b$ ) evaluated for the attenuated spectrum $j(l$ or $h)$. $\mu_{\mathrm{ij}}$ values can be numerically computed straightforwardly from the input spectra $\phi_{1}(E)$ and $\phi_{\mathrm{h}}(\mathrm{E})$ and energy-dependent attenuation coefficients $\mu_{\mathrm{a}}(\mathrm{E})$ and $\mu_{\mathrm{b}}(\mathrm{E})$. Having evaluated the $\mu_{\mathrm{ij}}$ values, the $\mathrm{k}_{\mathrm{ij}}$ values can be computed as the inverse matrix of $\mu_{\mathrm{ij}}$ according to Equations 17 through 20.

The noise variances of image signals, $\sigma_{\mathrm{p}_{1}}{ }^{2}$ and $\sigma_{p_{\mathrm{h}}}{ }^{2}$, in Equations 11 and 12 can be evaluated from the input spectra, $\phi_{1}(E)$ and $\phi_{h}(E)$, and energy-dependent attenuation coefficients, $\mu_{\mathrm{a}}(\mathrm{E})$ and $\mu_{b}(E)$, as follows:

$$
{\sigma_{\mathrm{P}}, \mathrm{h}}^{2}=\int d \mathrm{ER}_{\mathrm{l}, \mathrm{h}} \phi_{\mathrm{l}, \mathrm{h}}(\mathrm{E}) \mathrm{e}^{-\mu_{\mathrm{a}}(\mathrm{E}) \mathrm{t}_{\mathrm{a}}-\mu_{\mathrm{b}}(\mathrm{E}) \mathrm{t} \mathrm{h}} \mathrm{Q}(\mathrm{E})^{2}
$$

(Equation 22)

This has been the standard technique for computing the noise variance for a polychromatic x-ray spectrum. ${ }^{15}$ Equations 11; 12, and 17 through 22 provide the theoretical basis for the numerical studies to be discussed in the following sections.

\section{METHODS}

\section{Noise Variances in X-ray Signals}

Assuming that the subtraction signals are properly generated to accurately represent the actual soft tissue and bone thicknesses, the image contrast in the subtraction images should then be the same no matter which technique is used. Thus, the low-contrast performance should be determined only by the noise level in the subtraction images. Because it is generally the soft tissue that is of diagnostic interest in chest imaging, we have focussed our computations on the tissue-specific image. To be able to use Equation 11 to estimate the noise variance in the tissue image signal, $\sigma_{\mathrm{t}_{\mathrm{a}}}{ }^{2}$, we need to compute the coefficients, $k_{a j}$ values, and noise ratios associated with the $\mathrm{x}$-ray signals, $\sigma_{\mathrm{p}_{1}} / \mathrm{p}_{1}$ and $\sigma_{\mathrm{p}_{\mathrm{h}}} / \mathrm{p}_{\mathrm{h}}$. Both require the use of the low- and high-energy x-ray photon flux spectra $\phi_{1}(\mathrm{E})$ and $\phi_{\mathrm{h}}(\mathrm{E})$. For numerical simulation, $\phi_{1}(\mathrm{E})$ and $\phi_{\mathrm{h}}(\mathrm{E})$ were calculated in $1-\mathrm{keV}$ intervals from the published spectra ${ }^{12}$ and attenuation coefficients for the filters used. ${ }^{13}$

For the dual-kV(p) technique, $\phi_{\mathrm{l}}(\mathrm{E})$ and $\phi_{h}(E)$ are two independent spectra specific to the $\mathrm{kV}(\mathrm{p})$ values, target angle, and intrinsic filtration used. For the dual-filter technique, they were generated from the same spectrum, $\phi_{0}(\mathrm{E})$, but filtered differently as follows:

$$
\phi_{l, \mathrm{~h}}(\mathrm{E})=\phi_{0}(\mathrm{E}) \mathrm{e}^{-\mu_{1, \mathrm{~h}}(\mathrm{E}) \mathrm{t}_{\mathrm{l}, \mathrm{h}},}
$$

where $\mu_{l}(E)$ and $t_{l}$ are the attenuation coefficients ahd thickness for the low-energy beam filter (tungsten) and $\mu_{h}(E)$ and $t_{h}$ are those for the high-energy beam filter (copper). For the sandwich detector technique, $\phi_{h}(E)$ was generated from $\phi_{1}(\mathrm{E})$ as follows:

$$
\phi_{\mathrm{h}}(\mathrm{E})=\phi_{0}(\mathrm{E}) \mathrm{e}^{-\mu_{\mathrm{l}}(\mathrm{E}) \mathrm{t}-\mu_{\mathrm{f}}(\mathrm{E}) \mathrm{t}},
$$

where $\mu_{l}(E)$ and $t_{l}$ are the attenuation coefficients and thickness for the front detector (BaFBr:Eu storage phosphor) and $\mu_{f}(E)$ and $t_{f}$ are those for the interdetector filter (copper).

The filtered photon spectra were normalized to a total exposure of $10 \mathrm{mR}$ using published data. For simplicity, the soft tissue was assumed to consist of pure muscle only. Attenuation coeffi- 
cients and compositions for muscle and bone were taken from previously published data. ${ }^{14}$ The average attenuation coefficients were calculated using Equation 21. The results were then used to compute $\mathrm{k}_{\mathrm{ij}}$ values in accordance with Equations 17 and 18 . The variance of the $x$-ray signals was calculated by dividing the spectrum into $1-\mathrm{keV}$ intervals, calculating the variance for each interval first and then summing the results over the entire energy range.

For all techniques, the detectors were assumed to be a BaFBr:Eu storage phosphor screen whose absorption coefficients are known. The storage phosphors are normally used as an area detector in digital radiography. However, because of their ability to emit fluorescent light during the x-ray exposure, they can also be used with linear diode arrays for slit-scan imaging.

\section{Patient Exposure}

Patient exposure is often used as a measure for the risk to the patient in diagnostic imaging or measurement. Therefore, the noise variance should be computed for a fixed total patient exposure for optimization of comparison purposes. However, the image noise is directly related to the exposure received by the detector rather than the $x$-ray output or exposure received by the patient. Depending on the imaging geometry, various detector exposures may result from the same patient exposure. Therefore, for fair comparison, our comparisons were made for a fixed total unattenuated detector exposure (defined as the exposure to the detector when no patient or any other attenuator is present in the $\mathrm{x}$-ray beam). Given any imaging geometry, the patient entrance exposure can be computed from this exposure via the inverse square law. For instance, assuming that the patient entrance plane and detector are 12 and 72 inches away from the x-ray source, a detector exposure of $10 \mathrm{mR}$ corresponds to approximately $15 \mathrm{mR}$ of patient entrance exposure.

\section{Optimization}

Before comparison, each of the three techniques was optimized to a limited extent. From Equations 11 and 12, the noise levels in the subtraction images were determined by the noise ratios in low- and high-energy image signals and the coefficient $k_{i j}$ values. The former depends on (1) total unattenuated detector exposure (fixed for comparison), (2) distribution of the exposure between low- and highenergy image acquisition (exposure ratio), and (3) attenuation by the patient's body (tissue and bone thicknesses). The latter depends on (1) $\mathrm{kV}(\mathrm{p})$ levels of the $\mathrm{x}$-ray sources, (2) filtration of the incident $\mathrm{X}$-ray beams (filter types and thicknesses), and (3) filtration by the front and interdetector filter in the sandwich detector approach.

Although all aforementioned factors can be optimized to minimize the noise level in the subtraction images, the optimization is often limited by practical considerations. For instance, adjustment of the exposure ratio is virtually impossible with the sandwich detector technique and is technically difficult in implementation with a slit-scan imaging system. Another fact is that the technique can be optimized for either tissue or bone images but not both, and only for a specific combination of tissue and bone thicknesses. Thus, the value of optimization is somewhat limited if one is interested in both tissue and bone images and/or in a wide range of tissue and bone thickness combinations.

In this study, we did not attempt to optimize all parameters. For the dual-kV(p) technique, the low-kV(p) value was maintained at 70 while the high- $\mathrm{kV}(\mathrm{p})$ value and exposure ratios, defined as the ratio of the low-kV(p) exposure to the total exposure, were varied and optimized. No additional beam filtration was considered. For the single-kV(p), dual-filter technique, both the $\mathrm{x}$-ray $\mathrm{kV}(\mathrm{p})$ value and filter (tungsten and copper) thicknesses were varied and optimized. The prefiltration exposures of the low- and high-energy beams were assumed to be identical to each other. For the sandwich detector technique, both the $\mathrm{x}$-ray $\mathrm{kV}(\mathrm{p})$ value and interdetector filter (copper) thickness were varied and optimized. No additional (prepatient) filtration was considered.

\section{Tissue and Bone Thicknesses}

The noise levels in the subtraction images are highly dependent on the attenuating thicknesses. Furthermore, the subtraction imaging technique can only be optimized for a specific combination of tissue and bone thicknesses. 
Therefore, we have chosen $10 \mathrm{~cm}$ tissue and 0.6 $\mathrm{cm}$ bone as the representative thickness combination for our studies. This combination roughly corresponds to the outer edges of the lung field where rib bone segments may overlap with an intermediate tissue thickness.

\section{RESULTS AND DISCUSSION}

Spectra of Detected X-rays

With the nonlinear dual-energy subtraction techniques, it is unnecessary to completely separate the low- and high-energy spectra from each other. None of the three techniques results in completely separated spectra. Figure 1 shows a typical set of spectra generated for the dual$\mathrm{kV}(\mathrm{p})$ technique. The low- and high-energy $\mathrm{x}$-rays are assumed to be generated at 70 and $120 \mathrm{kV}(\mathrm{p})$ and attenuated by $10 \mathrm{~cm}$ of tissue and $0.6 \mathrm{~cm}\left(1 \mathrm{~g} / \mathrm{cm}^{3}\right)$ of bone. Figure 2 shows a typical set of spectra generated for the dualfilter technique. The $\mathrm{x}$-rays are assumed to be generated at $120 \mathrm{kV}(\mathrm{p})$ and filtered by $0.1 \mathrm{~mm}$ of tungsten and $1 \mathrm{~mm}$ of copper to form the lowand high-energy beams. Both beams are also assumed to transmit through $10 \mathrm{~cm}$ tissue and $0.6 \mathrm{~cm}$ bone before entering the detectors. Figure 3 shows the typical spectra for x-rays detected by the low- (front) and high-energy (back) detectors in the sandwich detector technique. The $\mathrm{x}$-rays were assumed to be generated at $120 \mathrm{kV}(\mathrm{p})$ and attenuated by $10 \mathrm{~cm}$ of tissue and $0.6 \mathrm{~cm}$ of bone before entering the front detector. The interdetector filter is a $0.5-\mathrm{mm}$ thick copper plate.

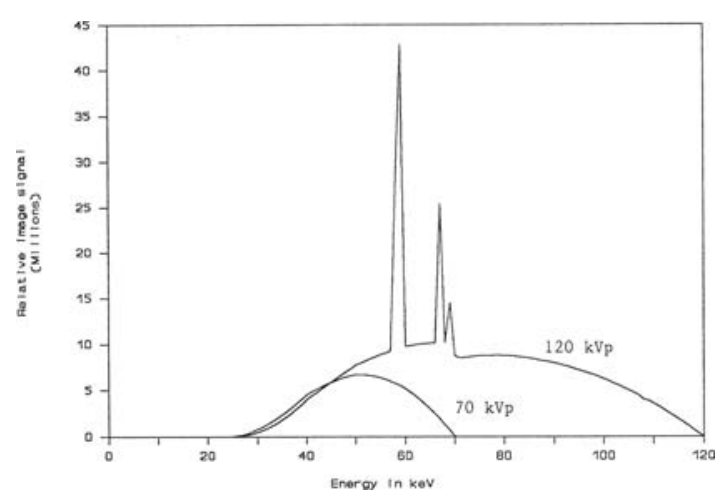

Fig 1. Spectra of detected $x$-rays computed for the dual$k V(p)$ technique. The low- and high-energy $x$-rays were assumed to be generated at $70 \mathrm{kV}(p)$ and $120 \mathrm{kV}(p)$, respectively.

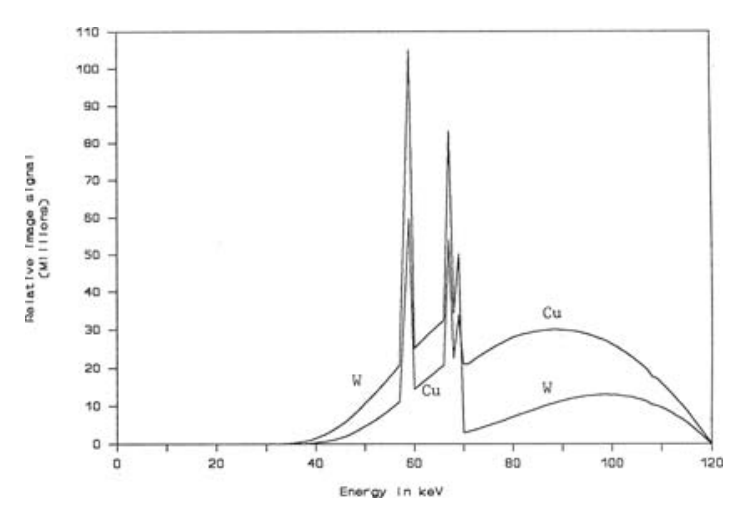

Fig 2. Spectra of detected $x$-rays for the dual-filter technique. The low- and high-energy $x$-rays were assumed to be generated at $120 \mathrm{kV}(\mathrm{p})$ and filtered by $0.14 \mathrm{~mm}$ of tungsten and $1 \mathrm{~mm}$ of copper, respectively.

\section{Dual-kV(p) Technique}

In Figure 4, the noise level in the tissue image signal has been plotted as a function of the exposure ratio for the dual- $k V(p)$ technique. The plots were made for several different $k V(p)$ values of the high-energy $x$-ray spectrum. The $\mathrm{kV}(\mathrm{p})$ value for the low-energy spectrum is kept fixed at 70 . The plots show that the exposure ratio should be kept around 50\% to minimize the noise. However, the dependence of the noise on the exposure ratio is less sensitive when the $\mathrm{kV}(\mathrm{p})$ value's difference is large. The noise level decreases with the $k V(p)$ value of the high-energy beam, ranging from approximately $0.04 \mathrm{~cm}$ for $80 \mathrm{kV}(\mathrm{p})$ to $0.01 \mathrm{~cm}$ for 140 $\mathrm{kV}(\mathrm{p})$.

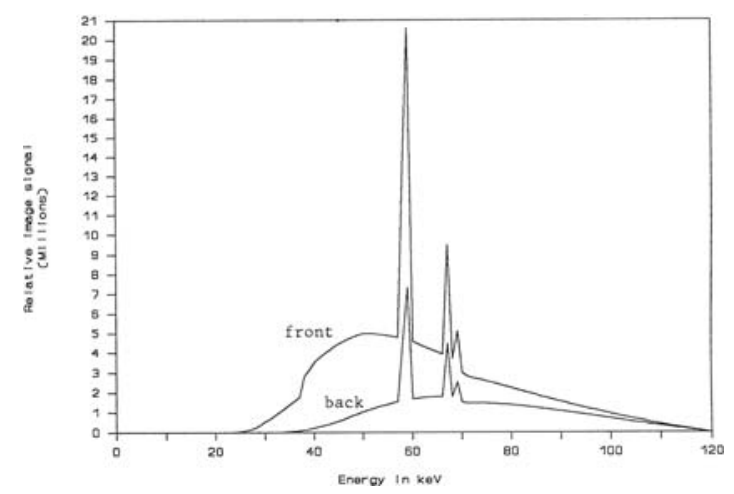

Fig 3. Spectra of detected $x$-rays computed for the sandwich detector technique. The $x$-rays were assumed to be generated at $120 \mathrm{kV}(\mathrm{p})$ and filtered by $0.5 \mathrm{~mm}$ of copper between the front and back detectors. 


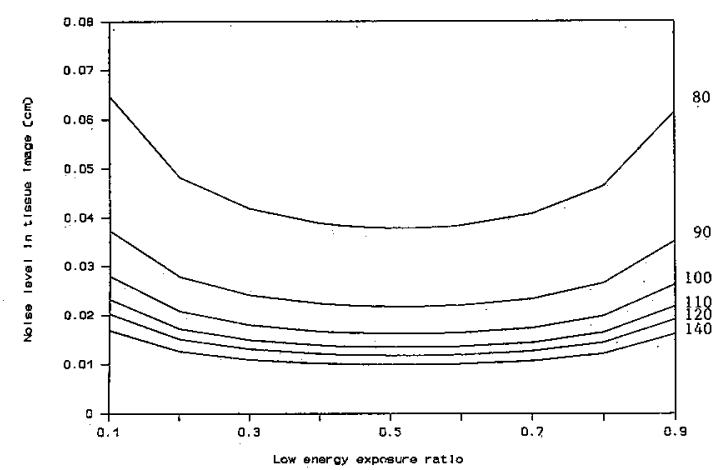

Fig 4. Noise level in the tissue image versus the exposure ratio (ratio of low-kV(p) exposure to the total exposure). The low-kV(p) was kept fixed at 70 while the high-kV(p) was varied from 80 to 140 .

\section{Dual-filter Technique}

Noise in the single-kV(p), dual-filter technique is dictated by the $\mathrm{kV}(\mathrm{p})$ value of the $\mathrm{x}$-ray source and thicknesses of the tungsten and copper filters used. However, for each copper thickness used, there is an optimal tungsten thickness that would minimize the noise level in the tissue image (for a specific combination of tissue and bone thicknesses). We have varied the copper thickness from 0.1 to $1 \mathrm{~cm}$ and numerically determined the corresponding optimal tungsten thickness. In Figure 5, the resulting noise (minimized) is plotted as a function of the copper thickness for several different $k \mathrm{~V}(\mathrm{p})$ values. The plots show that the optimal $k V(p)$ value for the single $\mathrm{kV}(\mathrm{p})$ tungsten and copper filter technique is between 110 and $120 \mathrm{kV}(\mathrm{p})$. With 1-mm copper filtration, all $\mathrm{kV}(\mathrm{p})$ values result in a noise level slightly below $0.04 \mathrm{~cm}$.

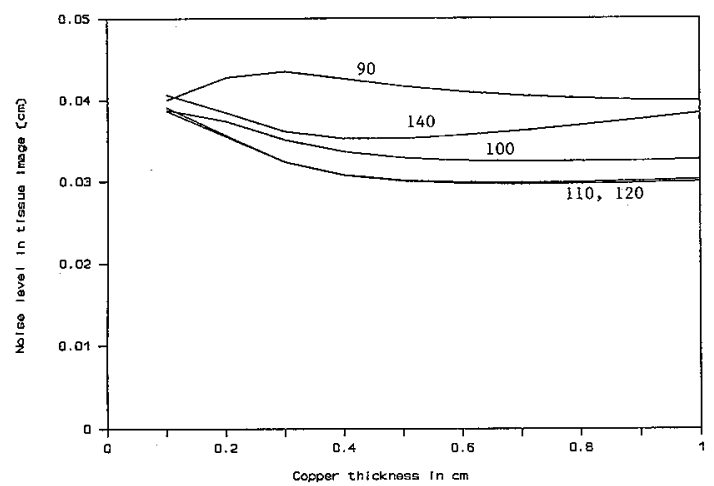

Fig 5. Noise level in the tissue image versus copper filter thickness for various $k V(p)$ values. An optimal tungsten filter thickness was computed and used with each different copper filter thickness.
When the $k V(p)$ lies between 110 and 120 $\mathrm{kV}(\mathrm{p})$, the noise level can be further reduced to about $0.03 \mathrm{~cm}$ with $4-\mathrm{mm}$ copper filtration.

\section{Sandwich Detector Technique}

Noise in the sandwich detector technique is dictated by the $k V(p)$ value of the incident $\mathrm{x}$-rays and thickness of the copper filter used. In Figure 6, the noise level in the tissue image signal is plotted as a function of the copper filter thickness for several different $\mathrm{kV}(\mathrm{p})$ values. The plots show that the optimal $\mathrm{kV}(\mathrm{p})$ value is greater than $90 \mathrm{kV}(\mathrm{p})$. A noise level of $0.04 \mathrm{~cm}$ can be achieved by using a copper filter with a thickness of $0.4 \mathrm{~mm}$ or greater.

\section{CONCLUSIONS}

To compare the three techniques from the same perspective, the noise level has been plotted as a function of the $\mathrm{kV}(\mathrm{p})$ value for each technique in Figure 7. The noise level was computed for a fixed patient exposure and minimized by selecting the optimal filter thicknesses or exposure ratio. As expected, the dual $\mathrm{kV}(\mathrm{p})$ results in the lowest noise level. The dual-filter and sandwich detector techniques result in approximately three and four times higher noise levels, respectively. It should be noted that to reduce these noise levels to that of the dual-kV(p) technique, the $\mathrm{x}$-ray output must be increased by factors of 9 and 16 for the dual-filter and sandwich detector techniques, respectively. This would reduce noise levels in the raw image data and therefore noise levels in the subtraction images. However, this also leads to a significantly increased patient exposure.

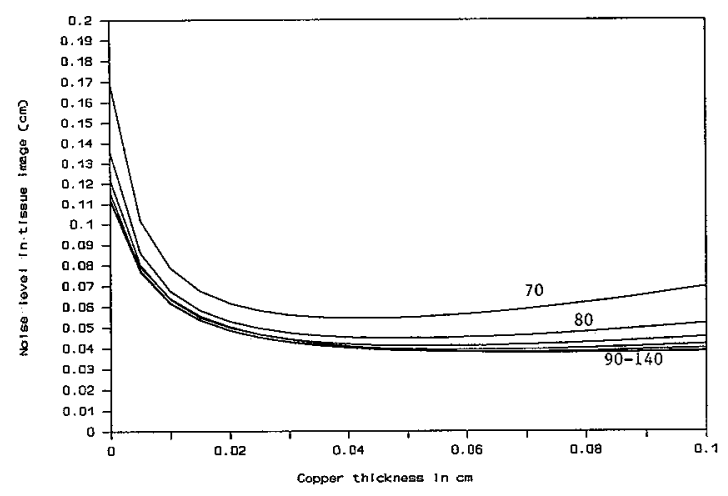

Fig 6. Noise level in the tissue image versus the interdetector copper filter thickness for various $k V(p)$ values. 


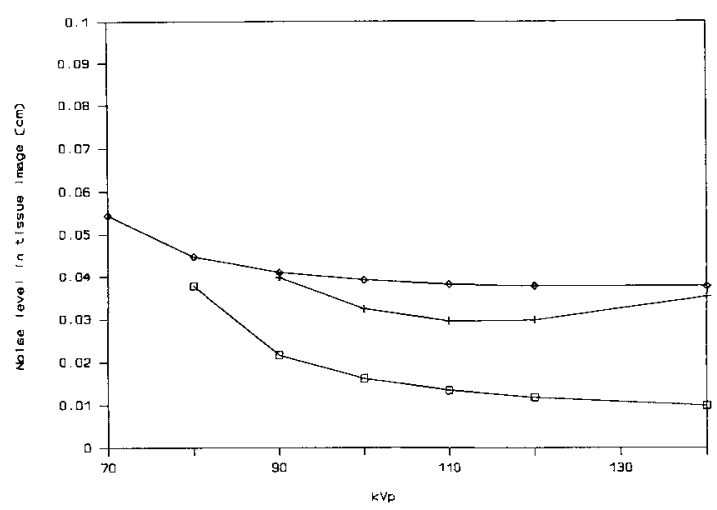

Fig 7. Noise level in the tissue image versus $k V(p)$. The noise was computed for a fixed patient exposure and minimized by choosing the optimal exposure ratio or filter thicknesses. $\square$, Dual $k V(p)$; +, dual filter; $\diamond$, dual detector.

Thus, the dual-kV(p) technique should be the preferred approach for dual-energy subtraction imaging if noise is the only concern. However, to minimize motion artifacts, the dual- $\mathrm{kV}(\mathrm{p})$ technique should be implemented by combining rapid $\mathrm{kV}(\mathrm{p})$ value switching with linear detector array imaging. To equalize the low- and high$k V(p)$ exposures, the high- $k V(p) x$-rays should be generated at lower current, or alternatively a copper filter can be inserted to attenuate the $\operatorname{high}-\mathrm{kV}(\mathrm{p}) \mathrm{x}$-rays. The advantage associated with this approach is a further improvement of the spectral separation and therefore further reduction of the subtraction noise. However, the incorporation of rapid filter change in synchronization with the $\mathrm{kV}(\mathrm{p})$ value change with a slit-scan imaging system is not a trivial task.

The dual-filter technique results in slightly lower noise than the sandwich detector tech-

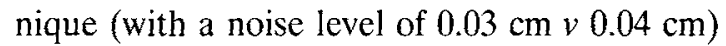
only at the optimal $\mathrm{kV}(\mathrm{p})$ values (110 to 120 $\mathrm{kV}[\mathrm{p}])$. However, this better performance is achieved at the expense of heavy filtration. A tungsten filter with a thickness of $0.5 \mathrm{~mm}$ or greater and a copper filter with a thickness of 5 $\mathrm{mm}$ or greater are required for generating the low- and high-energy x-ray beams. Their use would require the $\mathrm{x}$-ray tube output to be increased by a factor of 60 to 65 to achieve the same exposure level obtained without any filtration. This represents a big disadvantage for the dual-filter technique when it comes to actual implementation. This disadvantage is further aggravated by the fact that the $\mathrm{x}$-ray tube output must be further increased by a factor of as high as 200 to accommodate the slit-scan imaging technique. The sandwich detector technique, on the other hand, benefits little from prepatient filtration and therefore does not require an increase of the x-ray output. Thus, despite its slightly poorer noise properties, the sandwich detector technique seems to be a much more practical approach.

\section{REFERENCES}

1. Brody WR, Cassel DM, Sommer FG, et al: Dualenergy projection radiography: Initial clinical experience. AJR Am J Roentgenol 137:201,205, 1981

2. Niklason LT, Hickey NM, Chakraborty DP, et al: Simulated pulmonary nodules: Detection with dual-energy digital versus conventional radiography. Radiology 16():589593,1986

3. Nishitani H, Umezu Y, Kazuhisa O, et al: Dual-energy projection radiography using condenser $x$-ray generator and digital radiography apparatus. Radiology 161:533-535, 1986

4. Brody WR, Butt G, Hall A, et al: A method for selective tissue and bone visualization using dual energy scanned projection radiography. Med Phys 8:353-357, 1976

5. Barnes GT, Sones RA, Tesic MM, et al: Detector for dual-energy digital radiography. Radiology 156:537-540, 1985

6. Ishigaki T, Sadayuki S, Yoshimi H, et al: One-shot dual-energy subtraction imaging. Radiology 161:271-273, 1986

7. Oestmann JW, Greene R, Rhea JT, et al: Singleexposure dual energy digital radiography in detection of pulmonary nodules and calcifications. Invest Radiol 24:517521,1989
8. Stewart BK, Huang HK: Single-exposure dual-energy computed radiography. Med Phys 17:866-875, 1990

9. Shaw C, Plewes DB: Effects of scattered radiation and veiling glare in dual-energy tissue-bond imaging: A theoretical analysis. Med Phys 14:956-967, 1987

10. Cardinal HN, Fenster A: An accurate method for direct dual-energy calibration and decomposition. Med Phys 17:327-341, 1990

11. Chung $\mathrm{K}$, Huang HK: A fast dual-energy computational method using isotransmission lines and table lookup. Med Phys 14:186-192, 1987

12. Birch R, Marshall M, Ardran GM: Catalogue of spectra data for diagnostic x-rays. London, England, The Hospital Physicists' Association, 1979

13. Storm E, Israel HI: Photon cross sections from $1 \mathrm{keV}$ to $100 \mathrm{MeV}$ for elements $Z=1$ to $Z=100,{ }^{*}$ in Nuclear Data Tables. A7:565-681, New York, NY, Academic, 1970

14. Johns HE, Cunningham JR: The physics of radiology. Springfield, IL, Thomas, 1983

15. Barnes GT: Radiographic mottle: A comprehensive theory. Med Phys 9:656-667, 1982 